\title{
IMPLICAÇÕES DA GLOBALIZAÇÃO E DA PADRONIZAÇÃO LINGUÍSTICA NOS PADRÕES DE LEGENDAGEM E O DIALETO VISUAL COMO ESTRATÉGIA PARA LEGENDAR A VARIAÇÃO LINGUÍSTICA
}

\author{
IMPLICATIONS OF GLOBALIZATION AND LINGUISTIC STANDARDIZATION IN \\ SUBTITLING STANDARDS AND VISUAL DIALECT AS A STRATEGY FOR \\ SUBTITLING LINGUISTIC VARIATION
}

\author{
IMPLICACIONES DE LA GLOBALIZACIÓN Y DE LA ESTANDARIZACIÓN \\ LINGÜÍSTICA EN LOS ESTÁNDARES DE SUBTITULADO Y EL DIALECTO \\ VISUAL COMO ESTRATEGIA PARA SUBTITULAR LA VARIACIÓN LINGÜÍSTICA
}

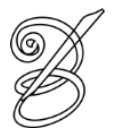 \\ Helena Santiago VIGATA* \\ Universidade de Brasília, Brasil \\ Patrícia Tavares da MATA** \\ Universidade de Brasília, Brasil
}

\begin{abstract}
Resumo: Globalização e padronização caminham juntas. A padronização linguística é um elemento importante para garantir a unidade de uma língua e, no caso do espanhol, é uma característica fortemente presente nas políticas linguísticas e na consciência dos falantes. O século XXI tem testemunhado a construção de uma nova política linguística pan-hispânica e o planejamento de uma norma pluricêntrica do espanhol na qual nenhuma variedade deve se impor sobre as demais. Mas, apesar do discurso institucionalizado em favor da unidade do espanhol e de seu fortalecimento como língua de globalização, continuam sendo produzidas traduções diferentes para o espanhol peninsular e o americano, conhecido no meio da tradução como espanhol neutro: uma variedade que se propõe a evitar usos excessivamente localizados. Esta variedade, utilizada também nos noticiários e em algumas telenovelas produzidas para difusão internacional com a intenção de abranger o maior número de espectadores, surgiu nas comunidades de prática como uma construção a muitas mãos desenvolvida de maneira empírica por tradutores e comunicadores sem o amparo de uma padronização oficial. O espanhol neutro tem reconhecimento oficial em vários países, mas ainda apresenta lacunas consideráveis que precisam ser problematizadas. Além da padronização linguística, a globalização e os avanços tecnológicos têm provocado importantes mudanças nos padrões de legendagem existentes para as diferentes línguas. Este trabalho apresenta um breve histórico dessa evolução e analisa alguns exemplos de tradução para discutir as repercussões negativas que o excessivo apego à norma padrão e ao espanhol neutro pode ter no poder expressivo das legendas de filmes e séries, resultando numa linguagem asséptica que, além de apagar as marcas da oralidade, neutraliza traços dos personagens que dizem respeito a seu estado psicológico, idade, gênero e procedência geográfica e social. Também é trazida à tona a necessidade de um novo olhar para lidar com a legendagem de palavrões e de filmes multilíngues e, por fim, são exploradas as possibilidades criativas do dialeto visual como estratégia para legendar a variação linguística.
\end{abstract}

Palavras-chave: Globalização. Padronização. Legendagem. Espanhol neutro. Dialeto visual.

Abstract: Globalization and standardization go hand in hand. Linguistic standardization is an important element to guarantee the unity of a language and, in the case of Spanish, it is strongly present both in the language policies and in the speakers' awareness. The 21st century has witnessed the construction of a new Pan-Hispanic

VIGATA, Helena Santiago. Implicações da globalização e da padronização linguística nos padrões de legendagem e o dialeto visual como estratégia para legendar a variação linguística. Belas Infiéis, Brasília, v. 8, n. 4, p. 69-89, 2019. 
linguistic policy and the planning of a Spanish pluricentric norm in which no variety should prevail over the others. But, despite the institutionalized discourse in favour of the unity of Spanish and its strengthening as a language of globalization, separate translations are still produced for Castilian and Latin American Spanish, the latter known in the translation world as neutral Spanish: a variety that is intended to avoid localized linguistic uses. This variety, also used in television newscasts and even in some soap operas produced for international broadcasting with the intention to reach the largest audience, arouse in the communities of practice as a collective construction developed empirically by translators and communicators without the support of an official standardization. Although neutral Spanish has official recognition in several countries, it still presents important gaps that need to be tackled. Globalization and technological advances have not only led to linguistic standardization, they have also brought important changes in the existing subtitling standards for the different languages. The aim of this paper is to present a brief history of this evolution and to analyse some examples of translations in order to discuss the negative effects that the excessive adherence to the standard norm and to neutral Spanish may have in the expressive power of film and series subtitles, resulting in an aseptic language that, besides erasing the marks of orality, neutralizes characters' traits that inform us about their psychological state, age, gender and geographical and social origins. This paper also poses the need for a new approach to the subtitling of expletives and multilingual films and explores the creative possibilities of the visual dialect as a strategy for capturing linguistic variation.

Keywords: Globalization. Standarization. Subtitling. Neutral Spanish. Visual dialect.

Resumen: La globalización y la estandarización van de la mano. La estandarización lingüística es un factor importante para la garantía de la unidad de una lengua y, en el caso del español, es una característica ampliamente presente tanto en las políticas lingüísticas como en la conciencia de los hablantes. El s. XXI ha presenciado la construcción de una nueva política lingüística panhispánica y la planificación de una norma pluricéntrica del español donde ninguna variedad debe imponerse sobre las demás. Pero, a pesar del discurso institucionalizado a favor de la unidad del español y de su fortalecimiento como lengua de globalización, se siguen produciendo traducciones distintas para el español peninsular y el americano, conocido en el medio de la traducción como español o castellano neutro: una variedad que procura evitar usos excesivamente localizados. Esta variedad, utilizada también en los noticiarios y en algunas telenovelas producidas para su difusión internacional con la intención de alcanzar el mayor número posible de espectadores, surgió en las comunidades de práctica como una construcción a muchas manos creada de forma empírica por traductores y comunicadores sin el amparo de una estandarización oficial. El español neutro goza de reconocimiento oficial en varios países, pero aún presenta lagunas considerables que deben ser cuestionadas. Además de la estandarización lingüística, la globalización y los avances tecnológicos han provocado importantes transformaciones en los estándares de subtitulado existentes para los diferentes idiomas. Este trabajo presenta un breve panorama de esa evolución y analiza algunos ejemplos de traducción para discutir las repercusiones negativas que puede tener en el poder expresivo de los subtítulos de películas y series el apego excesivo a la norma estándar y al español neutro, cuyo resultado es un lenguaje aséptico que, además de borrar las marcas de la oralidad, neutraliza los rasgos que perfilan el estado psicológico, la edad, el género y la procedencia geográfica y social de los personajes. También se trae a colación a lo largo del trabajo la necesidad de un nuevo enfoque para abordar el subtitulado de palabrotas y de películas multilingües y, por último, se exploran las posibilidades creativas del dialecto visual como estrategia para subtitulara la variación lingüística.

Palabras clave: Globalización. Estandarización. Subtitulado. Español neutro. Dialecto visual.

RECEBIDO EM: 15/02/2019

ACEITO EM: 20/08/2019

PUBLICADO EM: 10/2019

$\overline{\text { VIGATA, Helena Santiago. Implicações da globalização e da padronização linguística nos padrões de }}$ legendagem e o dialeto visual como estratégia para legendar a variação linguística. Belas Infiéis, Brasília, v. 8 , n. 4, p. 69-89, 2019. 


\section{Introdução}

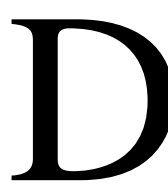

e acordo com Eriksen (2007), até o final da década de 1980 a palavra globalização era raramente utilizada, inclusive no meio acadêmico. Apesar denos séculos XVIII e XIX já se teorizasse sobre a interconectividade global, foi só depois da Guerra Fria que o interesse na globalização e nos fenômenos transnacionais cresceu devido, segundo o autor, aos seguintes fatores: a possibilidade de se pensar num único mercado global após a dissolução dos dois blocos que dividiram a mundo durante mais de quatro décadas, a crescente presença da internet e dos telefones celulares e o destaque que ganharam as políticas de identidade (nacionalista, étnica, religiosa), sendo os debates sobre imigração e multiculturalismo frequentes no ocidente.

O autor aponta oito categorias para analisar as diversas dimensões da globalização: descontextualização, aceleração, padronização, interconectividade, movimento, mistura, vulnerabilidade e recontextualização ${ }^{1}$. Comentamos cada uma delas a seguir.

Graças às mudanças tecnológicas e econômicas, é possível transportar de um lado a outro do globo ideias, música, livros, capital inversor, modas e mão de obra, o que tem implicações culturais e políticas importantes, pois estes deixam de estar imbricados a uma forma de vida social localmente fixada - ou seja, sofrem uma descontextualização. Desse modo, um Governo nacional pode declarar uma guerra a uma entidade não territorializada, como a guerra contra "o terror", que justifica classificar como inimigos terroristas localizados em qualquer parte do mundo (ERIKSEN, 2007, p. 15). Da mesma forma, no setor da indústria cultural, um oligopólio determinado pode ter total controle sobre mercados de várias regiões, estabelecendo quais bens têm potencial de vendas e redefinindo seus estilos para adequá-los ao padrão comercial internacional (GARCÍA CANCLINI, 2004, p. 244). Por outro lado, a descontextualização pode ser combatida mediante políticas identitárias nacionais e subnacionais.

Apesar de os cruzamentos entre culturas não serem uma realidade nova, cada vez são mais numerosos e diversificados, daí que Eriksen proponha considerar a mistura como uma categoria de análise da globalização. Na cena cultural, as atuais tecnologias da informação e da comunicação permitem uma mistura cultural nunca vista.

A aceleração é um aspecto que diz respeito ao aumento da velocidade dos transportes e da comunicação, graças ao qual longas distâncias já não estão necessariamente associadas à ruptura ou distanciamento temporal das relações. Além disso, os crescentes fluxos de 
migrações e de viagens a trabalho, para estudos ou de turismo têm tido um grande impacto nas políticas, economias e comunidades locais, motivo pelo qual o movimento pode ser considerado como uma categoria importante da globalização.

A interconectividade também é um fenômeno do mundo globalizado. As redes que conectam as pessoas são cada vez mais densas e rápidas. Criam-se conexões transnacionais complexas que envolvem uma relação de dependência mútua e a necessidade de estabelecer mais acordos internacionais, reformular as políticas externas e criar novos campos de oportunidades, correndo o risco de também sofrer restrições e opressão. A globalização pode ainda provocar nos territórios uma sensação de vulnerabilidade pelo enfraquecimento das fronteiras e pela impossibilidade de combater sozinhos problemas planetários como a mudança climática. Essa percepção de vulnerabilidade tem influenciado as políticas territoriais e internacionais contemporâneas.

Embora todas as categorias mencionadas tenham relação com o tema deste trabalho, a que mais interessa a este trabalho é a padronização. Prolifera em nossos dias todo tipo de instrumentos de padronização, tanto no nível nacional (como as normas publicadas pela 72 Associação Brasileira de Normas Técnicas - ABNT), quanto inter-regional (como as do Comitê Europeu de Normalização - CEN) e internacional (normas ISO, da Organização Internacional de Normalização). Os processos de padronização iniciados com o nacionalismo e as economias nacionais intensificaram-se com a globalização, trazendo comparabilidade e padrões compartilhados que permitem realizar transações econômicas entre agentes de diversos países. Mesmo quando as medidas de peso, comprimento, potência e moeda adotadas pelos agentes envolvidos divergem, existem métodos precisos de conversão que garantem sua comparabilidade. A consolidação do inglês como a língua de comunicação científica ou de negócios internacional também pode ser considerada como uma forma de estabelecer um padrão compartilhado. É importante lembrar que, como consequência da padronização, muitas práticas, crenças, habilidades e ofícios são levados ao desaparecimento pelo fato de fugirem à norma estabelecida (ERIKSEN, 2007, p. 56). O mesmo acontece com línguas que não passaram por processos de padronização.

Todas as categorias listadas podem encontrar resistência e evoluir em direções contrárias. Por exemplo, como resposta à descontextualização se podem produzir situações recontextualizadoras. Além disso, uma análise dessas categorias pode levar à conclusão de que certas localidades e regiões sofrem desglobalização. Conforme observa García Canclini 
(2004, p 253), "a diversidade cultural e o reconhecimento das minorias começam a ser vistos como requisitos para que a globalização seja menos injusta e mais inclusiva".

\section{Padronização linguística e espanhol neutro}

Das categorias acima apresentadas, a padronização tem sido apontada por Moreno Fernández (2017) como um dos traços mais sólidos do espanhol, a diferença do inglês, que, devido à sua interconectividade e descontextualização, apresenta uma maior vulnerabilidade e um nível inferior de padronização. A norma padrão do espanhol é, segundo Demonte Barreto (2001), geral e flexível, e não está regida pelo princípio de domínio, senão pelos de coerência e complementariedade. Além disso, as noções de norma e de correção gozam de um elevado reconhecimento social na comunidade hispanofalante.

Embora até metade do século XIX a variedade padrão do espanhol peninsular fosse a norma central imposta em toda a comunidade hispanofalante e em meados do século $\mathrm{XX}$ ainda houvesse traços compartilhados por certas variedades do espanhol que não eram aceitos pelas normas dos respectivos países (ÁVILA, 2001), o século XXI tem vivido uma mudança importante com a construção de uma nova política linguística pan-hispânica e o planejamento de uma norma pluricêntrica do espanhol na qual nenhuma variedade deve se impor sobre as demais. Sempre existiu por parte de todos os países hispanofalantes o interesse por reforçar a unidade da língua, hoje especialmente necessária para manter o poder competitivo do espanhol como língua de globalização. A padronização é, nesse sentido, um instrumento fundamental para garantir essa união.

Apesar das políticas linguísticas e do discurso empregado sobre a unidade do espanhol, a divisão entre a variante europeia e a americana continua existindo. Isso fica especialmente evidente no âmbito da tradução - literária, cinematográfica, de documentação, softwares e sites -, pois a Espanha continua produzindo suas próprias traduções no padrão peninsular, enquanto os países hispano-americanos costumam compartilhar uma única tradução, produzida no que no âmbito da tradução é conhecido como espanhol neutro e no dos meios de comunicação, como espanhol internacional: um espanhol que evita usos excessivamente localizados. Essa variedade do espanhol, utilizada também nos noticiários e em algumas telenovelas produzidas para difusão internacional com a intenção de abranger o maior número de espectadores, surgiu nas comunidades de prática e à margem dos trabalhos de padronização de um espanhol pan-hispânico por parte das academias da língua. 
Ávila (2001) sugere que os profissionais dos meios de comunicação generalista utilizem como referência a base comum do espanhol e que, nos casos de divergência, prefiram as vozes com maior distribuição territorial dentro do mundo hispânico e número de falantes. Na hipótese de que a palavra ou expressão possa gerar mal-entendidos em certas regiões, ele recomenda evitá-la e recorrer a outra solução. Como resultado, o espanhol utilizado apresenta uma mistura de traços linguísticos de normas justapostas.

$\mathrm{O}$ argumento principal para defender o uso do espanhol neutro ou internacional é que acaba sendo economicamente viável. Outro argumento utilizado é que presumivelmente permite uma comunicação compreensível para todos. Porém, esta tese não tem sido completamente comprovada. Em um experimento desenvolvido por Scandura (2018) com crianças argentinas acostumadas a assistir a filmes e desenhos animados dublados na variedade neutra com o intuito de testar sua compreensão de palavras que aparecem nas dublagens em espanhol neutro e que não fazem parte do repertório linguístico do espanhol da Argentina, os resultados mostraram que a maioria delas não tinham incorporado ainda essas unidades lexicais a seus repertórios passivos da língua. Por exemplo, quase todas as crianças

74 falharam em entender a acepção da palavra tenis que remete ao calçado esportivo, pois, para elas, o vocábulo se refere unicamente ao esporte com esse nome.

Não devemos esquecer que a variedade padrão é um modelo ideal de referência que apenas uma minoria de pessoas que se policiam e cultivam seus hábitos linguísticos são capazes de falar e escrever de acordo com a norma. Inclusive, isso só é necessário em situações formais onde se espera um certo nível de e propriedade (MORENO CABRERA, 2006). Da mesma maneira, a pretensão universalista do espanhol internacional tem uma maior adequação a contextos formais de comunicação, pois, conforme nos afastamos do registro formal, a variação linguística aumenta entre os falantes e entre suas variedades, tornando difícil encontrar denominadores comuns. Perante a ausência de fontes de consulta que auxiliem o profissional na eleição de uma voz em detrimento de outras com base em critérios sólidos, a intuição e o método de escolha por eliminação acabam sendo os elementos norteadores das escolhas linguísticas. Se, ainda, nos encontramos diante do desafio de traduzir uma obra com características estilísticas próximas da oralidade e do registro informal, a neutralização das marcas dialetais e coloquiais desvirtuará por completo a obra. Essa é uma realidade que precisa ser mais problematizada nos meios profissional e acadêmico. Há países que aceitaram oficialmente a variedade neutra; na Argentina, inclusive, foi promulgada uma 
lei em 1986 que exigia seu uso na dublagem, e essa exigência também foi aplicada na legendagem. Mas questões importantes continuam sem ser resolvidas. Contra o discurso institucionalizado em favor da unidade do espanhol e de seu fortalecimento como língua de globalização, continuam sendo produzidas versões diferentes para o espanhol peninsular e o americano, sendo este último uma construção a muitas mãos desenvolvida de maneira empírica por tradutores e comunicadores, sem o amparo de uma padronização oficial.

Podemos tomar como exemplo da desvirtuação da obra pelo espanhol neutro as legendas do DVD oficial de Tropa de Elite (2007), de José Padilha. Esqueda (2012) analisou as estratégias utilizadas pelo tradutor para lidar com os palavrões encontrados na primeira hora do filme e sua análise mostrou que, das 83 ocorrências encontradas, 45 foram omitidas, 30 neutralizadas e 1 traduzida por equivalência ou imitação. A tradução de palavrões nas legendas tem sido tradicionalmente atenuada pela ideia de que o texto escrito tem um impacto muito maior do que o texto oral. Além disso, podemos apontar como uma possível causa para a omissão de alguns dos palavrões as restrições espaçotemporais impostas pelo meio. Mas é evidente que outros fatores de peso interferiram no resultado, sendo provavelmente o principal deles a preocupação do tradutor em utilizar uma variedade neutra. Até onde sabemos, no Brasil, os legendistas não costumam receber das produtoras manuais específicos para suas línguas trabalho a não ser do português. E, quando trabalham diretamente com o cliente, a maioria das vezes, recebem o filme sem nenhuma especificação sobre qual variante utilizar, ficando com eles a responsabilidade de tal decisão. Na pretensão de abranger o maior público possível, o normal é que se procure um espanhol menos marcado. Portanto, no caso de Tropa de Elite tendemos a descartar a hipótese de que as restrições viessem impostas por normas ou pela censura do cliente. Como bem observa Esqueda (2012, p. 147), os palavrões neste filme não são apenas emitidos pelos traficantes ou por pessoas de classes mais baixas, mas também "pelos membros do batalhão da Tropa de Elite, pelos diretores dos presídios, pelos governantes, por outros cidadãos ditos comuns e também por aqueles de classes mais abastadas [...] que se mostram indignados com a realidade que vivem". Ou seja, os palavrões possuem uma carga expressiva importante que deveria ser mantida na tradução. Com intuito de empregar uma variedade neutra, o tradutor acabou criando uma versão caricata e inverossímil que destoa da raiva e da brutalidade com a que falam os personagens. Ninguém imaginaria um daqueles homens em situação de máximo estresse dizendo “¡Diablos!", 
“iMaldición!” o “iMaldita sea!”, até porque essas expressões estão em desuso na maior parte da comunidade hispanofalante.

Ao ver os resultados da pesquisa de Esqueda, decidimos fazer um pequeno estudo para saber como profissionais da linguagem originários de diversos países hispanofalantes traduziriam alguns dos enunciados do trailer do filme. Os cinco participantes que aceitaram o desafio são professores de espanhol ou de tradução em instituições de ensino superior brasileiras. Não foi imposta nenhuma norma ou restrição, simplesmente lhes pedimos que procurassem traduções o mais próximas possíveis de sua variante de espanhol. No quadro a seguir podemos comparar a versão do DVD com as traduções para o espanhol feitas pelos participantes de Colômbia, Paraguai, Espanha, Cuba e Uruguai.

Quadro 1 - Falas do filme com sua tradução em espanhol neutro e em outras cinco variantes.

\begin{tabular}{|c|c|c|c|c|c|c|}
\hline Original & Neutro & Colômbia & Paraguai & Espanha & Cuba & Uruguai \\
\hline $\begin{array}{l}\text { Embora, } \\
\text { porra! }\end{array}$ & $\begin{array}{l}\text { ¡Fuera! } \\
\text { (del } \\
\text { automóvil } \\
\text { ) }\end{array}$ & $\begin{array}{l}\text { ¡Nos } \\
\text { fuimos, } \\
\text { hijueputa! }\end{array}$ & $\begin{array}{l}\text { ¡Vamos, } \\
\text { carajo! }\end{array}$ & $\begin{array}{l}\text { ¡Vamos, } \\
\text { coño! }\end{array}$ & $\begin{array}{l}\text { ¡Vamos, } \\
\text { pinga! }\end{array}$ & $\begin{array}{l}\text { ¡Vámosnos } \\
\text { ! ¿La puta } \\
\text { que lo } \\
\text { parió! }\end{array}$ \\
\hline Caralho! & $\begin{array}{l}\text { ¡Diablos! } \\
\text { / } \\
\text { maldición } \\
\text { / maldita } \\
\text { sea }\end{array}$ & ¡Mierda! & ¡Carajo! & ¡Joder! & $\begin{array}{l}\text { ¿Carajo/co } \\
\text { jones! }\end{array}$ & $\begin{array}{l}\text { ¡Qué lo } \\
\text { parió! }\end{array}$ \\
\hline $\begin{array}{l}\text { Já avisei } \\
\text { que vai dar } \\
\text { merda, } \\
\text { isso. }\end{array}$ & $\begin{array}{l}\text { Le dije } \\
\text { que era } \\
\text { uma mala } \\
\text { idea. }\end{array}$ & $\begin{array}{l}\text { Ya se las } \\
\text { canté que } \\
\text { eso va a } \\
\text { ser una } \\
\text { cagada. }\end{array}$ & $\begin{array}{l}\text { Ya avisé } \\
\text { que eso no } \\
\text { va a salir } \\
\text { bien. }\end{array}$ & $\begin{array}{l}\text { Ya te dije } \\
\text { que la iban } \\
\text { a cagar. }\end{array}$ & $\begin{array}{l}\text { Yo dije que } \\
\text { esto iba a } \\
\text { dar } \\
\text { mierda. }\end{array}$ & $\begin{array}{l}\text { Ya les dije } \\
\text { que eso va } \\
\text { a ser una } \\
\text { mierda. }\end{array}$ \\
\hline $\begin{array}{l}\text { Aponta } \\
\text { essa porra! }\end{array}$ & ¡Señálalo! & $\begin{array}{l}\text { ¡Apunte } \\
\text { esa } \\
\text { maricada } \\
!\end{array}$ & $\begin{array}{l}\text { ¡Apuntá esa } \\
\text { mierda! }\end{array}$ & $\begin{array}{l}\text { ¡Apunta esa } \\
\text { mierda! }\end{array}$ & $\begin{array}{l}\text { ¡Apunta } \\
\text { esa } \\
\text { mierda! }\end{array}$ & $\begin{array}{l}\text { ¡Apuntá } \\
\text { esa } \\
\text { mierda! }\end{array}$ \\
\hline $\begin{array}{l}\text { Qual é? } \\
\text { Esse aqui, } \\
\text { de } \\
\text { jaqueta? É } \\
\text { tu mesmo, } \\
\text { filho da } \\
\text { puta! }\end{array}$ & $\begin{array}{l}\text { ¿El de la } \\
\text { chaqueta? } \\
\text { Ven acá. }\end{array}$ & $\begin{array}{l}\text { ¿Cuál es? } \\
\text { ¿Este, el } \\
\text { de } \\
\text { chaqueta? } \\
\text { ¡Hágase } \\
\text { el } \\
\text { güevón!, } \\
\text { ¿no? }\end{array}$ & $\begin{array}{l}\text { ¿Qual és? } \\
\text { Este acá de } \\
\text { chaqueta? } \\
\text { ¡Eres vos, } \\
\text { hijo de } \\
\text { puta! }\end{array}$ & $\begin{array}{l}\text { ¿Quién es? } \\
\text { ¿Este de } \\
\text { aquí, el de } \\
\text { la chupa? } \\
\text { ¡Eres tú, } \\
\text { hijo de } \\
\text { puta! }\end{array}$ & $\begin{array}{l}\text { ¿Cuál es, } \\
\text { este aquí } \\
\text { de } \\
\text { chaqueta? } \\
\text { ¡Tú mismo, } \\
\text { hijueputa! }\end{array}$ & $\begin{array}{l}\text { ¿Cuál es? } \\
\text { ¿Ese de } \\
\text { chaqueta? } \\
\text { ¡Eres tú } \\
\text { mismo, } \\
\text { hijo de } \\
\text { puta! }\end{array}$ \\
\hline
\end{tabular}




\begin{tabular}{|c|c|c|c|c|c|c|}
\hline $\begin{array}{l}\text { Deu sorte, } \\
\text { hein, } \\
\text { vagabundo } \\
\text { ? }\end{array}$ & $\begin{array}{l}\text { Tuviste } \\
\text { suerte, } \\
\text { vago. }\end{array}$ & $\begin{array}{l}\text { Está es } \\
\text { ligado, } \\
\text { ¿no, mi } \\
\text { nero? }\end{array}$ & $\begin{array}{l}\text { Tenes } \\
\text { suerte, ¿eh, } \\
\text { vagabundo } \\
\text { ? }\end{array}$ & $\begin{array}{l}\text { Tuviste } \\
\text { suerte, ¿eh, } \\
\text { gilipollas? }\end{array}$ & $\begin{array}{l}\text { Tuvo } \\
\text { suerte el } \\
\text { vagabund } \\
\text { o. }\end{array}$ & $\begin{array}{l}\text { Tuvimos } \\
\text { suerte, } \\
\text { ¿eh? } \\
\text { Canalla. }\end{array}$ \\
\hline
\end{tabular}

Fonte: pesquisa.

Como podemos comprovar nos exemplos apresentados, todos os participantes utilizaram em sua tradução palavrões de seu próprio repertório e que em alguns casos coincidem entre si e em outros não. Mesmo que um espectador desconhecesse o significado de alguns dos palavrões, não deixaria de inferir, pelo contexto, a presença de linguagem vulgar condizente com o que está acontecendo no filme. Já a versão em espanhol neutro distancia-se totalmente do texto e delega toda a força do filme na interpretação dos personagens, em sua expressividade corporal e prosódica. Conforme conclui Esqueda (2012, p. 159), ao neutralizar a linguagem, foram neutralizados também as características dos personagens e o conflito pelo que estão passando.

\section{Padrões de legendagem}

Assim como o resto de serviços e produtos, as legendas são objeto de normas que pautam uma série de diretrizes gerais a serem seguidas para garantir um padrão de qualidade. Além disso, cada produtora trabalha com seus próprios manuais de estilo.

Pedersen (2018) chega a uma interessante conclusão em sua análise da evolução das normas e diretrizes de legendagem ao longo dos anos, notadamente influenciada pela evolução tecnológica, que pode ser desmembrada em três momentos-chave: a chegada do código de tempo eletrônico na década de 1980, o surgimento dos DVDs e o boom da televisão comercial na década seguinte e, por fim, a transmissão de vídeos sob demanda na presente década. A cada fase, as normas foram adotando um teor mais global.

Partiu-se de uma situação na qual as diretrizes eram elaboradas e usadas internamente pelos tradutores que trabalhavam nas próprias emissoras de televisão, como a BBC no Reino Unido. Com a chegada dos computadores pessoais e do código de tempo eletrônico, que permitia fazer a marcação dos tempos, ganhou-se precisão na exibição das legendas e foi possível aumentar a velocidade de leitura. Mais tarde, com o surgimento do DVD e a proliferação de multinacionais que emitiam internacionalmente seus conteúdos nas mais diversas línguas, aumentou o número de empresas internacionais de legendagem, as quais,

VIGATA, Helena Santiago. Implicações da globalização e da padronização linguística nos padrões de legendagem e o dialeto visual como estratégia para legendar a variação linguística. Belas Infiéis, Brasília, v. 8, n. 4, p. 69-89, 2019. 
para otimizar os processos, criavam um arquivo de legendas na língua inglesa que serviria como matriz para todos os tradutores, os quais apenas teriam que se ocupar da tradução das legendas sem mexer na pietagem. Os tradutores recebiam os manuais de estilo correspondentes à sua língua, que costumam refletir os hábitos e preferências do público-alvo. Neste momento, os padrões de legendagem tenderam a uma harmonização para facilitar o compartilhamento e a gestão das diversas versões, mas ainda eram mantidas as especificidades locais para não provocar um excessivo estranhamento do público.

Com a chegada das plataformas de vídeo sob demanda, a tendência parece ter sido a adoção de uma norma única para todas as línguas e a criação de guias de estilo padronizados para cada uma que incluem os dicionários de referência correspondentes e alguns exemplos localizados. Ao contrário das normas criadas pelos funcionários das emissoras de televisão que começavam tendo um caráter descritivo para, aos poucos, irem se tornando mais prescritivas -, Pedersen (2018, p. 97) chega à conclusão de que os modelos do vídeo sob demanda fazem o caminho inverso: começam com umas diretrizes globais e prescritivas para, progressivamente, inserir novos elementos que descrevem e refletem as preferências locais.

78 Assim como na fase anterior, os tradutores recebem um arquivo matriz com as legendas já criadas na língua de partida e devem cuidar apenas da tradução dessas legendas, sem se preocupar com a marcação dos tempos. Podemos salientar uma mudança perceptível na maneira de gerir a documentação dessas plataformas: o acesso aberto, em contraposição ao secretismo dos modelos passados. Qualquer pessoa interessada pode, por exemplo, consultar online no site da Netflix as diretrizes gerais e os manuais de estilo, algo antes completamente impossível, pois apenas tinha acesso a esses documentos quem trabalhava para as empresas correspondentes. Outra novidade notável da fase atual é que qualquer usuário pode mandar seus comentários e sugestões para melhorar os manuais de estilo. Quando acatados pela Netflix, são incluídos na próxima atualização do manual. Dessa forma, a empresa vai adaptando seus manuais para adequá-los aos contextos com exemplos localizados. Nesse processo, é possível perceber outro elemento novo: a influência dos consumidores na atualização das diretrizes locais da plataforma.

Curiosamente, enquanto as empresas de legendagem internacional costumavam trabalhar com equipes diferenciadas e manuais de estilo independentes para traduzir os filmes e as séries para o espanhol peninsular (Castilian Spanish) e o americano (Latin American Spanish), a Netflix, que também oferece legendas nas duas variantes utiliza um manual único, 
apesar de ter manuais separados para o português de Portugal e o português do Brasil, que divergem em aspectos como o uso de espaço depois do hífen em legendas com dois interlocutores.

Os parâmetros de velocidade de leitura, número de linhas, limite de caracteres, uso de itálico e tradução de nomes de personagens são praticamente os mesmos para todas as línguas, salvo poucas exceções (PEDERSEN, 2018, p. 92) e os manuais têm estruturas similares com pontos bastante gerais (sobre uso de abreviações, acrônimos, nomes de personagens, uso de itálico etc.). Também em todos os manuais há uma seção sobre a presença de falas em línguas diferentes da língua de partida. Basicamente, a orientação é que sejam traduzidos apenas aqueles enunciados cuja compreensão por parte do espectador é esperada, como quando o filme original já vem com a legendagem parcial dessas falas. Se for para utilizar palavras em outra língua nas legendas, devem estar em itálico, a não ser que sejam nomes próprios ou unidades lexicais que já tenham sido incorporadas ao dicionário. Há uma seção de instruções especiais onde a maioria dos manuais explicita que o tradutor deve respeitar o teor dos diálogos e não censurar o uso de palavrões. Os dois últimos aspectos mencionados - a tradução de heterolinguismo e a de palavrões - são especialmente relevantes neste artigo, pois mostram as preferências atuais do público por uma manutenção do estilo e da variação linguística presente nos filmes. Pelas diretrizes da Netflix, não haveria razões para omitir ou neutralizar os palavrões do filme Tropa de Elite.

\section{Legendagem da variação linguística}

Nos últimos anos, o heterolinguismo tem ganhado protagonismo em filmes e séries devido a diversos fatores, dentre os quais podemos destacar a repercussão das políticas de preservação e valorização da diversidade linguística e cultural e a proliferação de coproduções internacionais. A variação linguística sempre foi um elemento importante na construção dos personagens, pois cada um deles porta traços linguísticos específicos que dizem respeito a seu estado psicológico, idade, gênero e procedência geográfica e social. Porém, essa variação tem sido sistematicamente apagada na legendagem, muitas vezes pelo conservadorismo linguístico dos tradutores que, em vez de tentar soluções mais ousadas para marcar a variação linguística, preferem se ater à norma culta e acabam criando uma linguagem asséptica (DÍAZ CINTAS, 2003, p. 245). 
Apesar de a função das legendas ser traduzir a linguagem oral, a norma escrita sempre foi preponderante na legendagem, provocando um distanciamento de registros entre o que era dito na tela e o que o espectador lia nas legendas. Desse modo, a perda de marcas da oralidade e dos traços dialetais era assumida como uma tendência natural. Se, ainda, analisarmos como vem sendo feita a legendagem de filmes multilíngues, comprovaremos que na maioria dos casos a tradução resultante foi um texto totalmente monolíngue ou com a diversidade linguística consideravelmente reduzida. Os manuais não especificavam como se devia lidar com este tipo de filmes e havia certo receio a deixar falas sem traduzir.

Só recentemente tem se percebido a necessidade de transgredir a norma para poder traduzir filmes e séries onde a variação linguística foi utilizada como elemento desencadeador de situações centrais do enredo, o que a torna impossível de ser ignorada na tradução. Ainda é perceptível certa resistência por parte dos tradutores a desvencilhar-se de seu passado profissional, que lhes impôs o uso da norma padrão, conforme aponta Silva (2018, p. 64) em sua pesquisa sobre o estilo pessoal do tradutor. Como vimos acima, o espanhol se caracteriza pelo elevado respeito à variedade padrão. Talvez por isso a Netflix não considerou necessário especificar em seu manual de estilo que os tradutores devem dar preferência aos usos gramaticais corretos, algo que encontramos no manual de estilo para o português do Brasil, que permite alguns usos não normativos (como "Eu te amo" ou "Me liga") nos casos em que a estrutura correta causaria o estranhamento do público.

Pinto (2009) sugere que há elementos não-padrões da língua portuguesa que são percebidos como mais graves pelo público em função de seu distanciamento da variedade padrão. A autora propõe organizar esses elementos num continuum onde os elementos lexicais que marcam usos regionais ou socioletais são os mais bem aceitos, seguidos pelas alterações gráficas e, por último, os elementos morfossintáticos, que recebem um alto nível de rejeição. Na Figura 1 ilustramos esse continuum com exemplos do português do Brasil. 
Figura 1 - Continuum dos elementos não-padrão da língua portuguesa

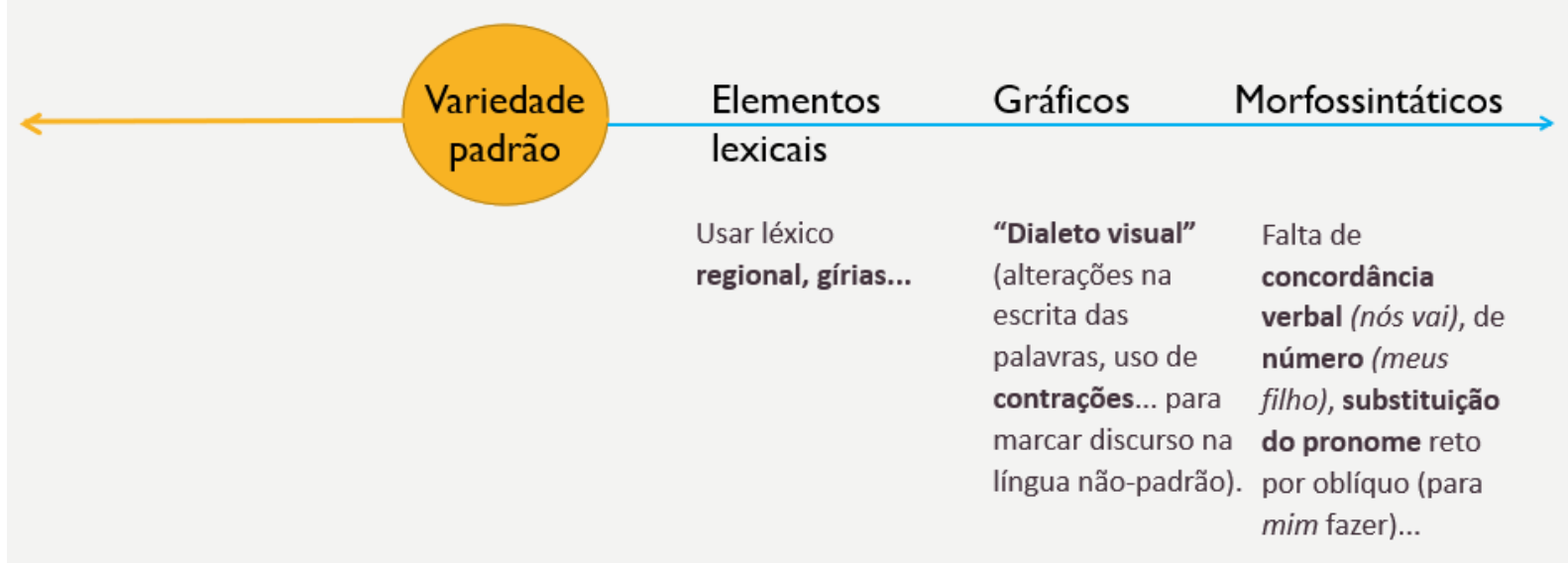

Fonte: elaborado a partir de Pinto, 2009.

Acreditamos que a mesma gradação pode ser aplicada no espanhol e arriscaríamos afirmar que a rejeição dos usos morfossintáticos não normativos é ainda maior do que no português do Brasil, por não ser tão estendidos. A seguir, exploramos as possibilidades de um recurso gráfico bastante utilizado na literatura e que tem sido aplicado de maneira criativa na legendagem de alguns filmes: o dialeto visual.

\section{Dialeto visual}

O dialeto visual é uma estratégia estilística que consiste em utilizar recursos da língua (fonológicos, morfológicos, sintáticos, semânticos e lexicais) com o objetivo de representar falantes de um grupo social ou regional, rompendo, assim, o horizonte de expectativas de leitura mediante uma escrita altamente oralizada.

A representação de dialetos para a caracterização de personagens é comumente utilizada na literatura. Pinto (2009) salienta que, apesar da importante função que os sotaques e dialetos exercem nesse contexto, é possível encontrar exemplos em que a representação literária de dialetos tende à conformidade com a norma padrão e são distantes das reais características das falas que se podem ouvir ao caminhar pelas ruas (PINTO, 2009, s.n.). Ainda segundo a autora, dialetos e sotaques em textos literários são em sua maioria recriações literárias, além disso, escritores se beneficiam de estereótipos linguísticos facilmente reconhecidos pelo grande público para auxiliar na caracterização de seus personagens.

No romance Tres tristes tigres (1967), do escritor cubano Guillermo Cabrera Infante, obra que o consagrou como um dos escritores hispano-americanos mais originais de sua época (ORTEGA, 1969, p. 11), destacamos a tentativa de reconstrução da oralidade dos 
personagens. Em seu livro, o autor imprime o dialeto dos subúrbios de Havana por meio da estratégia do dialeto visual. O romance é destacado pela crítica não apenas pela ruptura com os cânones da época, mas, também, pelo rompimento com os limites da linguagem escrita, que, segundo Ortega $(1969$, p. 36), se dá quando o autor transpassa barreiras do esperável no texto escrito com uma forma de representação do real onde a narrativa se torna independente da realidade como cópia ou reflexo e assume a linguagem como uma realidade única.

Em seu prefácio, sob o título "Advertência", Cabrera Infante explica ao referir-se à oralidade do livro:

o livro está em cubano. Ou seja, escrito nos diferentes dialetos do espanhol que se falam em Cuba, e a escrita não é mais que uma tentativa de capturar a voz humana no ar [...]. As diversas formas de cubano se fusionam, ou acho que se fusionam, numa só linguagem literária. No entanto, predomina como sotaque a fala dos havaneiros e, em particular, a gíria noturna, que, como em todas as grandes cidades, tende a ser um idioma secreto. A reconstrução não foi fácil e algumas páginas devem ser melhor ouvidas do que lidas (CABRERA INFANTE, 1967, p. 3, tradução nossa ${ }^{2}$, grifo nosso).

A reconstrução realizada pelo escritor diz respeito a sua tentativa de registrar novamente a palavra dita oralmente sobre outras bases (as da escrita), o que, em palavras de Ortega (1969, p. 39), constitui uma tentativa quase que metafísica de captar no ar a palavra, pois, em vez de remeter a uma oralidade fingida, nos transporta às ruas periféricas de Havana.

A escrita da oralidade nos convida a ir além da interpretação do significado semântico, atentando para a especificidade e características da forma, como as marcas de registro, ambiguidades, espontaneidade, velocidade, reformulações, tons, etc. A intenção de Cabrera Infante de refletir através da linguagem a multifacetada realidade cubana converte o romance em uma obra experimental com múltiplos discursos e estilos distintos. Nuessel (1982) verifica as técnicas, a consistência e o estilo utilizados pelo autor. É analisada a estratégia de dialeto visual, que consiste na modificação da ortografia convencional para representação de variedades linguísticas presentes na obra.

Tres tristes tigres apresenta uma grande variedade de recursos para representação da oralidade que não seriam possíveis de serem apresentados neste breve artigo, contudo, para exemplificação da técnica de dialeto visual utilizada pelo autor, destacamos os recursos segmentais (consoantes e vogais), como, por exemplo, a eliminação da letra $s$ em posição de coda $($ etá $=$ está, mimo $=$ mismo $)$ ou no final da palavra $($ lo farallone $=$ los farallones, má $=$ más, ere $=$ eres $)$, a perda da $d$ intervocálica ou no final da palavra (lao = lado, metía $=$ 
metida, uté $=$ usted edá $=e d a d)$, a redução consonântica $($ rimmo $=$ ritmo, dinno $=$ digno, correto $=$ correcto $),$ o seseo $^{3}($ dise $=$ dice, entonse $=$ entonces, hase $=$ hace $)$, a redução da vogal média /e/ $($ rialidá $=$ realidad $)$ o lambdacismo $($ vilgen $=$ virgen, hablal $=$ hablar , polque $=$ porque, puelta $=$ puerta $)$ ou a substituição do $r$ alveolar por $s$ alveolar $($ divestisme $=$ divertirme).

Também são realizadas alternâncias gráficas entre fonemas que em muitas regiões hispano-falantes têm a mesma pronúncia, o que costuma causar a confusão ortográfica de usuários da língua, como é o caso dos fonemas v/b (volbió $=$ volvió, benía $=$ venía $), \mathrm{j} / \mathrm{g}($ cojida $=$ cogida, jente $=$ gente $),$ e $l l / v($ yebava $=l l e v a b a$, tulla $=$ tuya $)$.

Além dos aspectos segmentais, a oralidade do livro se destaca pela utilização de recursos suprassegmentais, como a utilização da acentuação que permite representar a tonalidade da fala ou a utilização do apóstrofo que indica elisão de sons ou supressão de letras, como no exemplo extraído por Nuessel (1982, p. 217) do livro: “Aparato mágico qu'atrapa image po'medio d'impresió e' reflejo luminoso n'papel sensibilisao”. E também por recursos que indicam a velocidade na qual falam os personagens, como a hifenização para indicar um ritmo largo (o-y-e-l-o, ma-ra-bi-lla) ou a falta de pontuação ou separação entre palavras para marcar um ritmo presto (tevasencontlal $=$ te vas a encontrar, polequina $=$ por la esquina).

Em seu prefácio, Cabrero Infante adverte sobre o desafio que foi para ele representar, por meio da escrita, a oralidade do dialeto cubano, uma vez que a língua oral não tem uma norma escrita estabelecida e isso adiciona mais um desafio para o autor. A oralidade no decorrer das páginas vai proporcionando ao leitor uma verdadeira imersão nas periféricas ruas de Havana, além disso, os diferentes recursos utilizados e sua experimentação linguística convidam à emersão de um leitor ativo.

Se por um lado a técnica de dialeto visual na literatura é usual e a utilização de seus recursos para a caracterização de personagens é uma escolha do autor, por outro, a proposta de utilização desta na legendagem de produtos audiovisuais que possuam dialetos ou socioletos nos parece ser uma boa estratégia a ser utilizada pelo tradutor. A legendagem está associada à tradução diassemiótica (GOTTLIEB, 1998, p. 220), interpretação de informações do canal verbal oral para o canal verbal escrito. Contudo, para a produção das legendas, não são apenas os elementos verbais que devem ser levados em consideração, pois tudo que acompanhará o "texto", ou seja, toda a informação visualmente apresentada possui sua 
importância na composição da narrativa, assim como o que é falado, como é falado e as marcas de oralidade dos personagens também possuem sua relevância pragmática e semiótica.

No exemplo do documentário brasileiro de cunho ativista Catadores de História (2015), da diretora Tânia Quaresma, que retrata a vida e o engajamento político dos catadores de materiais recicláveis de diferentes regiões do Brasil, os protagonistas são pessoas de estrato social baixo e de pouca escolaridade. Suas narrativas exercem um papel de afirmação como classe social e, seu socioleto, de identidade cultural. Para a legendagem em espanhol desse documentário, a técnica de dialeto visual se apresentou na pesquisa de Mata (2018) como uma boa estratégia para marcação da oralidade dos catadores.

Inicialmente, o documentário foi legendado em espanhol por membros do grupo de pesquisa Acesso Livre, da Universidade de Brasília. As legendas foram escritas em espanhol padrão, de acordo com diretrizes atuais de legendagem profissional, o que resultou no apagamento, no texto, das marcas de oralidade dos discursos dos catadores. Levando em consideração o caráter ativista do filme, dar voz a uma comunidade socialmente marginalizada, aos discursos dos catadores e às suas marcas de oralidade exerce um papel 84 importante na proposta ativista do documentário. Dessa forma, foi apresentada uma nova proposta de legendagem inscrita na proposta de tradução ativista (BAKER, 2016; MORTADA, 2016) na qual o socioleto dos catadores fosse mantido. Para a busca de padrões linguísticos que pudessem indicar a presença do socioleto em espanhol, foram realizadas análises sociolinguísticas de documentários hispano-americanos que retratam pessoas do mesmo estrato social e que serviram como corpus comparável. Como resultado, temos uma legendagem que se utiliza da técnica de dialeto visual para manter a oralidade das falas dos catadores, como no exemplo do filme: "a coleta seletiva era pros trem vim limpo, mas tá vino uma bagacera só!", traduzido por "con la recolección selectiva, to'o debería venir limpio, ipero viene to'o mezclao!’, dessa maneira, consideramos que a tradução dialoga com a proposta ativista do filme.

A proposta de Mata não é único exemplo da utilização do dialeto visual para marcação da oralidade na legenda. As legendas oficiais da emissora de televisão pública TVN - Televisión Nacional de Chile nos chamam a atenção pelo uso do dialeto visual, que apresenta ao público a escrita da oralidade. Como no documentário chileno 21 días: ¿Cómo es vivir y trabajar en la basura? (2017), produzido e exibido pela emissora. O documentário retrata o cotidiano de catadores de materiais recicláveis que trabalham em aterros sanitários

VIGATA, Helena Santiago. Implicações da globalização e da padronização linguística nos padrões de legendagem e o dialeto visual como estratégia para legendar a variação linguística. Belas Infiéis, Brasília, v. 8 , n. 4, p. 69-89, 2019. 
nas regiões chilenas; eles são protagonistas de grande parte da narrativa e expressam em sua fala variação linguística com relação à norma padrão. Da marcação da oralidade na legenda do documentário, destacamos os exemplos: “'Care gallo que hay pa'arriba!”, “duré un año chantao”, “tu juntai toda la noche tus cosas pa' que te la roben, no po' ”. Em relação à tradução em espanhol, Nuessel (1982) destaca que sua ortografia é especialmente favorável para utilização do dialeto visual, pois em seu sistema ortográfico existe uma correspondência consistente e próxima entre os grafemas e os fonemas que representam. Para tal, destacamos a importância de se realizar um estudo sociolinguístico minucioso para a tradução de socioletos para que padrões linguísticos reais possam ser usados.

O dialeto visual apresenta-se como uma ótima técnica que pode auxiliar o tradutor na marcação da oralidade. Nos exemplos apresentados, escrever a língua oral é expressar outras formas de tratamento da diversidade que não tendam ao tratamento automatizado de moldar a língua oral aos padrões da língua escrita na legendagem. A tradução do socioleto e o emprego de fenômenos linguísticos reais da língua de chegada é uma forma de expressar a identidade sociocultural do grupo e alinhar a legendagem com a agenda do documentário. Sem a devida atenção às vozes e lutas das classes socialmente marginalizadas, a padronização dos discursos significaria a anulação da real expressividade de suas vozes. Dessa maneira, também é possível atuar para assegurar a autonomia cultural e linguística dessas comunidades. Pois, conforme aponta Brisset (1996, p. 165), a tradução pode ser "um ato de reivindicação, de recentralização de identidade e uma operação de reterritorialização" (tradução nossa ${ }^{4}$ ).

\section{Considerações finais}

Este trabalho se propôs a analisar as implicações da globalização e da padronização linguística nos padrões de legendagem e tentou demostrar que, apesar da inegável importância de criar padrões linguísticos e técnicos para facilitar a comunicação e a circulação internacional de filmes legendados, o excesso de uniformidade pode ser prejudicial. Afinal, como afirma Demonte Barreto (2001), aceitar cegamente a padronização como instrumento de nivelação de via única fere a natural tendência à variação que caracteriza as línguas.

Foram comentados exemplos de falas do filme Tropa de Elite cuja tradução oficial deixou a desejar pela excessiva neutralização e omissão da linguagem vulgar que caracteriza o estilo do filme. Aos poucos parece estar se produzindo uma mudança nos padrões linguísticos da legendagem visando a produzir traduções mais próximas do estilo do filme. A linguagem

VIGATA, Helena Santiago. Implicações da globalização e da padronização linguística nos padrões de legendagem e o dialeto visual como estratégia para legendar a variação linguística. Belas Infiéis, Brasília, v. 8, n. 4, p. 69-89, 2019. 
tabu não precisa mais ser censurada e as falas em línguas diferentes da língua de partida nem sempre precisam ser traduzidas, possibilitando que o filme traduzido mantenha o caráter multilíngue do original. Embora ainda exista uma resistência considerável à produção de legendas com elementos não normativos, especialmente os morfossintáticos, vemos que começa a haver exceções à regra.

Em uma realidade global em que as trocas de informações se dão de maneira dinâmica e as fronteiras são cada vez mais transpassadas pela interconectividade e as redes que aproximam diferentes culturas, um ponto importante a se (re)pensar é a garantia de que aspectos de uma cultura não sejam apagados nesse movimento de quase homogeneização cultural. Nesse contexto, acreditamos que marcar a oralidade, o registro e as marcas dialetais dos personagens na legendagem é uma forma de resistência em um movimento que confere ao tradutor sua importante atribuição e lhe faz repensar suas escolhas linguísticas em lugar de cair no tratamento automatizado de moldar a língua falada e seus inúmeros recursos aos padrões da língua escrita.

O tradutor, nessa situação, se depara com a árdua tarefa de transpor os diversos matizes da linguagem oral para o texto, mas tem a seu dispor todos os recursos fonológicos, morfológicos, sintáticos, semânticos e lexicais da língua. Conforme mostramos neste artigo, um uso criativo e criterioso do dialeto visual pode se tornar uma boa estratégia para a reconstrução das marcas de oralidade e da variação linguística.

$\mathrm{Na}$ pesquisa realizada por Mata (2018) para a aplicação do dialeto visual na legendagem do filme Catadores de História, podemos observar a importância de registrar graficamente o socioleto dos catadores e catadoras como um ato de reivindicação/reconhecimento da diversidade linguística de culturas subjugadas, em que se torna possível "reivindicar as variações [linguísticas] como identidade cultural do grupo, como língua própria, com características advindas de contatos com outras culturas além da cultura do colonizador" (MATA, 2018, p. 39), em um movimento que também pode ser engajador e descolonizador, capaz de valorizar a diversidade linguística.

\section{REFERÊNCIAS BIBLIOGRÁFICAS}

ÁVILA, Raúl. Los medios de comunicación masiva y el español internacional. In: II CONGRESO INTERNACIONAL DE LA LENGUA ESPAÑOLA: EL IDIOMA ESPAÑOL EN LA SOCIEDAD DE LA INFORMACIÓN. Anais [...]. Valladolid, 2001. Disponível em: https://cvc.cervantes.es/obref/congresos/valladolid/ponencias/unidad_diversidad_del_espanol/ 1_la_norma_hispanica/avila_r.htm. Acesso em: 2 out. 2019. 
BAKER, Mona. Translating dissent: Voices from and with the Egyptian revolution.

Abingdon: Routledge, 2016.

BRISSET, Annie. A Sociocritique of Translation. Toronto: University of Toronto Press, 1996.

CABRERA INFANTE, Guillermo. Tres tristes tigres. Barcelona: Seix Barral, 1967.

DEMONTE BARRETO, Violeta. El español estándar (ab)suelto: algunos ejemplos del léxico y la gramática. In: CVC. II CONGRESO INTERNACIONAL DE LA LENGUA ESPAÑOLA: EL ESPAÑOL EN LA SOCIEDAD DE LA INFORMACIÓN. Anais [...]. Valladolid, 2001. Disponível em:

https://cvc.cervantes.es/obref/congresos/valladolid/ponencias/unidad_diversidad_del_espanol/ 1_la_norma_hispanica/demonte_v.htm. Acesso em: 2 out. 2019.

DÍAZ CINTAS, Jorge. Teoría y práctica de la subtitulación: inglés / español. Barcelona: Ariel, 2003.

ERIKSEN, Thomas Hylland. Globalization: The Key Concepts. Oxford/New York: Berg, 2007.

ESQUEDA, Marileide Dias. O filme Tropa de Elite em espanhol: a questão da tradução dos palavrões. Abehache, ano 2, n. 3, p. 145-161, 2012.

GARCÍA CANCLINI, Néstor. Diferentes, desiguais e desconectados: mapas da interculturalidade (3. ed.). Traduzido por: Luiz Sérgio Henriques. Rio de Janeiro: UFRJ, 2004.

GOTTLIEB, Henrik. Subtitles and International Anglification. Nordic Journal of English Studies, Copenhagen, p. 229-230, 1998.

MATA, Patrícia Tavares da. Legendagem Ativista: a importância de marcar o socioleto no filme Catadores de História. Trabalho de Conclusão de Curso (Graduação) - Departamento de Línguas Estrangeiras e Tradução. Universidade de Brasília, Brasília, 2018.

MORENO CABRERA, Juan Carlos. Prejuicios sobre el euskera. Nabarraldek argitaratua, 2006. Disponível em: http://www.nabarralde.com/es/archivo/ekarpenak/3094-juan-carlosmoreno-cabrera-prejuicios-sobre-el-euskera. Acesso em: 2 out. 2019.

MORENO FERNÁNDEZ, Francisco. Sociolingüística de la globalización. In: Olímpio de Oliveira Silva, M. E; Penadés Martínez, M. I. (eds.). Investigaciones actuales en

Linguiística. Vol. I: Sobre la Lingüística y sus disciplinas. Alcalá de Henares: Servicio de Publicaciones de la Universidad de Alcalá, 2017, p.118-135.

MORTADA, Leil-Zahra. Translation and solidarity in Words of Women from the Egyptian Revolution. In: BAKER, Mona. Translating dissent voices from and with the Egyptian revolution. Abingdon: Routledge, 2016. p. 88-96. 
NETFLIX. Brazilian Portuguese Timed Text Style Guide. Disponível em: https://partnerhelp.netflixstudios.com/hc/en-us/articles/215600497-Brazilian-PortugueseTimed-Text-Style-Guide. Acesso em: 2 out. 2019.

NETFLIX. Castilian and Latin American Spanish Timed Text Style Guide. Disponível em: https://partnerhelp.netflixstudios.com/hc/en-us/articles/217349997-Castilian-LatinAmerican-Spanish-Timed-Text-Style-Guide. Acesso em: 2 out. 2019.

NUESSEL, Frank. Eye Dialect in Spanish: Some Pedagogical Applications. Hispania: A Journal Devoted to the Teaching of Spanish and Portuguese, 65(3), p. 346-51, 1982.

ORTEGA, Julio. La contemplación y la fiesta. Caracas: Monte Ávila Editores. 1969.

PEDERSEN, Jan. From old tricks to Netflix: How local are interlingual subtitling norms for streamed television? Journal of Audiovisual Translation, 1(1), p. 81-100, 2018.

PINTO, Sara Ramos. How important is the way you say it? A discussion on the translation of linguistic varieties. Target 21, n. 2, p. 289-307, 2009.

SCANDURA, Gabriela. El español neutro para el doblaje: mitos y realidades. Trabalho apresentado no Congreso Hispanoamericano de Traducción Audiovisual. Buenos Aires, 2018.

88 SILVA, Janailton Mick Vitor da. Que espaço a legendista ocupa? Um estudo sobre estilo do tradutor. 2018. 176 f. Dissertação (Mestrado em Estudos da Tradução) - Departamento de Línguas Estrangeiras e Tradução. Universidade de Brasília, Brasília, 2018.

\section{Referências Audiovisuais}

TROPA de Elite. Direção: José Padilha. 2007. 1 filme (118 min). DVD.

CATADORES de História. Direção: Tânia Quaresma. 2015. 1 filme (75 min).

21 DÍAS: ¿Cómo es vivir y trabajar en la basura? Direção: Catalina Castro, 2017. (61 min). Disponível em: https://www.youtube.com/watch?v=AoXsUWNTF_M. Acesso em: 3 out. 2019.

\footnotetext{
*Helena Santiago VIGATA - Doutora em Comunicação (2016) pela Universidade de Brasília. Mestre em Linguística Aplicada (2011) pela mesma instituição. Realizou mestrado profissional em Ensino do Espanhol como Segudna Língua (2011) na Universidad Nacional de Educación a Distancia, Espanha. É especialista em Tradução e localização de videojogos (2019) pela Instituto Superior de Estudios Linguí́sticos y Traducción, Espanha. É especialista em Tradução Audiovisual (2002) pela Universitat Autònoma de Barcelona, Espanha. É graduada em Tradução e Interpretação (2002) pela mesma instituição. É professora adjunta na Universidade de Brasília. Brasília, Distrito Federal, Brasil.

Currículo acadêmico: http://lattes.cnpq.br/9968961018763883

ORCID: https://orcid.org/0000-0002-2396-9653

E-mail: helena.santiago.vigata@gmail.com

${ }^{* *}$ Patrícia Tavares da MATA - Graduanda do Bacharelado em Línguas Estrangeiras Aplicadas ao Multilinguismo e à Sociedade da Informação da Universidade de Brasília. Foi bolsista de iniciação científica 2017-2018. Membro do grupo Tradução Audiovisual e Acessibilidade a pessoas Cegas e Surdas (Acesso Livre). Brasília, Distrito Federal, Brasil.
}

VIGATA, Helena Santiago. Implicações da globalização e da padronização linguística nos padrões de legendagem e o dialeto visual como estratégia para legendar a variação linguística. Belas Infiéis, Brasília, v. 8 , n. 4, p. 69-89, 2019. 
Currículo acadêmico: http://lattes.cnpq.br/4837938246988148

ORCID: https://orcid.org/0000-0002-2976-5918

E-mail: ptavaresdamata@gmail.com

${ }^{1}$ Tradução nossa do inglês: disembedding, acceleration, standarization, interconnectedness, movement, mixing, vulnerability e re-embedding.

2 "El libro está en cubano. Es decir, escrito en los diferentes dialectos del español que se hablan en Cuba y las escrituras no es más que un intento de atrapar la voz humana al vuelo [...]. Las distintas formas del cubano se funden o creo que se funden en un solo lenguaje literario. Sin embargo, predomina como un acento el habla de los habaneros y en particular la jerga nocturna, que como en todas las grandes ciudades, tiende a ser un idioma secreto. La reconstrucción no fue fácil y algunas páginas se deben oír mejor que se leen".

${ }^{3}$ Seseo é o nome em espanhol para o fenômeno da fala que consiste em pronunciar o $z$ e o $c$ como /s/ quando vão antes de $e, i$ em contraposição ao ceceo, mais comum em regiões do espanhol peninsular, que consiste em pronunciar o $z$ e o $c$ nessa mesma posição como $[\theta]$.

4 "Translation becomes an act of reclaiming, of recentering of the identity, a re-territorializing operation".

VIGATA, Helena Santiago. Implicações da globalização e da padronização linguística nos padrões de legendagem e o dialeto visual como estratégia para legendar a variação linguística. Belas Infiéis, Brasília, v. 8, n. 4, p. 69-89, 2019. 